\title{
TCM in Egypt towards Better Practice
}

Amal Fehr ${ }^{1^{*}}$, Fatma El-Noby ${ }^{1}$, Abeer Abdelhady Tony ${ }^{2}$ and Effat Tony ${ }^{3}$

${ }^{1}$ Rheumatology and Physical Medicine Department, Faculty of Medicine, Aswan University, Egypt

${ }^{2}$ Neurology Department, Faculty of Medicine, Aswan University, Egypt

${ }^{3}$ General Medicine Departments, Faculty of Medicine, Assuit University, Egypt

*Corresponding author: Fehr A, Rheumatology and Physical Medicine Department, Faculty of Medicine, Aswan University, Egypt. Tel: +201006706822; E-mail: amalfehr@yahoo.com

Received date: June 28, 2016; Accepted date: October 03, 2016; Published date: October 06, 2016

Copyright: (c) 2016 Fehr A, et al. This is an open-access article distributed under the terms of the Creative Commons Attribution License, which permits unrestricted use, distribution, and reproduction in any medium, provided the original author and source are credited.

\section{Commentary}

Egyptians which number almost one hundred million habitats have skilled medical practioners in all modern medical fields and they had as well-known history dated since pharos for medical herbal and unique healing procedures but they know little about Traditional Chinese Medicine (TCM) except that natural Chinese herbs (Materia Medica) and acupuncture are adequate for relieving pain and losing weight [1].

In recent years, some doctors have become more interested in TCM and have tried their best to introduce acupuncture to medical practice in Egypt with good response from the public in many private clinics but with limited scope of TCM knowledge and narrow spectrum of indications.

However acupuncture and other TCM therapeutic scope in Egypt should be increased to cover many other medical problems treated worldwide with TCM. Currently, there is only one acupuncture clinic in the public hospitals [1].

Egyptian government hasn't established yet a formal acupuncture educational system nor adopted legal regulation for its practice or malpractice, so there is no uniform way for practioners to learn acupuncture. As a result, expertise of the acupuncture practitioner is uneven and needs to be improved.

As mentioned before government hasn't set up a statute concerning the control of Chinese medicine; so many Chinese medical practices are not under supervision making this practice is liable to many malpractice events. The requirements and scope set up a good opportunity to allow Chinese acupuncture to be established in Egypt [2].

Comparatively, the pharmaceutical industry in Egypt is very skilled, and has built up an effective marketing system with an advanced industry standard. With the development of the economy and incomes, per capita consumption of medicines has increased steadily. The rate can reach to $5 \%$ to $7 \%$. Production of new medicines cannot meet demand for the lack of advanced techniques. As a result, there is the need to import medicines which takes up $7 \%$ of the consumption [3].

In the last few years, materia medica output in Egypt increased $10.7 \%$ and per capita consumption increased $8.5 \%$ annually. But the profit margin is only $20 \%$ because of the scarcity of patents, price controls and the small per capita consumption [4].

The government has supported underrepresented market development such as pharmaceutical plants including Chinese herbs that could put a new pharmacy industry in competition with that of other countries [5].
There are plenty of kinds of plants with great medicinal value in Egypt [6]. At present, there is local production and sales of such neutraceuticals as america ginseng tablets, aloe capsules, and honeysuckle tablets from china. Pharmaceuticals have to be registered first in order to be approved, produced and/or imported into Egypt [7]. Registration usually needs from several months to two or three years and can be really quite complex [8].

To enhance the TCM practice in Egypt, group of TCM practitioners succeeded to establish a clinical fellowship program which is planned to start soon to train Egyptian western medicine-oriented doctors on traditional medicine including TCM. This will be with the government of PRC's help in training Egyptian doctors either in china or in Egypt by inviting some Chinese doctors to visit Egypt.

At the end of this summary, TCM is an acceptable stream of medical practice for Egyptians based on their historical links to herbal medicine and natural healing procedures practiced by them since before history, but a governmental efforts are needed towards legalization of TCM and to establish a uniform educational TCM system in medical schools to qualify medical practitioners to be able to conduct TCM services.

Those all can be backboned by efforts from international societies such as WHO and other societies concerned with providing TCM as a complementary to western medical services specially in developing countries such as Egypt.

\section{References}

1. Birdee GS, Wayne PM, Davis RB, Phillips RS, Yeh GY (2009) T'ai chi and qigong for health: patterns of use in the United States. J Altern Complement Med 15: 969-973.

2. Chan E, Tan M, Xin J, Sudarsanam S, Johnson DE (2010) Interactions between traditional Chinese medicines and Western therapeutics. Curr Opin Drug Discov Devel 13: 50-65.

3. Li C, Moyle K, Xue C (2003) Problems and challenges with Chinese herbal medicine. In: Leung PC, Xue CC, Cheng YC (eds), A Comprehensive Guide to Chinese Medicine, World Scientific Publishing Ltd, Singapore.

4. Kaptchuk TJ (2000) The Web That Has No Weaver: Understanding Chinese Medicine. (2nd edn.), New York, McGraw Hill Professional, New York, USA.

5. Manheimer E, Wieland S, Kimbrough E, Cheng K, Berman BM (2009) Evidence from the Cochrane Collaboration for traditional Chinese medicine therapies. J Altern Complement Med 15: 1001-1014.

6. O'Brien K, Xue C (2003) The theoretical framework of chinese medicine. In: Leung PC, Xue CC, Cheng YC (eds), A Comprehensive Guide to Chinese Medicine, World Scientific Publishing Ltd, Singapore. 
Citation: Fehr A, El-Noby F, Tony AA, Tony E (2016) TCM in Egypt towards Better Practice. Altern Integr Med 5: 221. doi: $10.4172 / 2327-5162.1000221$

Page 2 of 2

7. Vickers AJ, Cronin AM, Maschino AC, Lewith G, MacPherson H, et al. (2012) Acupuncture for chronic pain: individual patient data metaanalysis. Arch Intern Med 172: 1444-1453.
8. Xue C, O'Brien K (2003) Modalities of Chinese medicine. In: Leung PC, Xue CC, Cheng YC (eds), A Comprehensive Guide to Chinese Medicine, World Scientific Publishing Ltd, Singapore. 